\title{
Synthesis of 2-Oxaadamantane Derivatives
}

\author{
E. A. Ivleva ${ }^{a} * *$, V. V. Klepikov ${ }^{a}$, Yu. E. Khatmullina ${ }^{a}$, V. B. Rybakov ${ }^{b}$, and Yu. N. Klimochkin ${ }^{a}$ \\ ${ }^{a}$ Samara State Technical University, Samara, 443100 Russia \\ ${ }^{b}$ Faculty of Chemistry, Moscow State University, Moscow, 119991 Russia \\ *e-mail: ivleva.ea@samgtu.ru
}

Received July 19, 2021; revised August 11, 2021; accepted August 14, 2021

\begin{abstract}
Dichloroadamantanes in fuming nitric acid were converted to mixtures of 2-oxaadamantane derivatives whose structure was determined by two-dimensional NMR methods and X-ray analysis. The resulting compounds can be used in the design of highly complex molecules as subjects for studying biological activity.
\end{abstract}

Keywords: 2-oxaadamantane, fuming nitric acid, transannular cyclization, Grob fragmentation

DOI: $10.1134 / \mathrm{S} 1070428022010043$

\section{INTRODUCTION}

Polycyclic cage structures containing oxaadamantane and polyoxaadamantane fragments occur in nature. Examples are tetrodotoxin (one of the most toxic nonprotein toxins isolated from fish of the order Tetraodontiformes), chiriquitoxin (nonprotein toxin isolated from the frog Atelopus chiriquiensis), daigremontianin (isolated from the tropical flower Kalanchoe daigremontiana), and fusidilactone $\mathrm{C}$ which showed antifungal activity [1] against Eurotium repens and Fusarium oxysporum. Among synthetic polyoxaadamantanes, trioxaadamantanetriols (trivially named bananins) showed a high inhibitory activity against coronavirus helicase (Nsp13) [2-4] (Fig. 1).

Compounds containing an oxaadamantane fragment have been used in the synthesis of biologically active structures [5-10]. Conformationally rigid crown ethers have been obtained from oxaadamantane derivatives, and some of them were shown to bind alkali metal cations with a selectivity comparable to that of known crown ethers such as 15-crown-5 and 18-crown-6 [11, 12].

There are two strategies for the construction of the 2-oxaadamantane system, the first of which is based on transannular cyclizations of bicyclo[3.3.1]nonane derivatives [13]. A number of 2-oxaadamantane derivatives were synthesized by cyclization of bicyclo[3.3.1]non-2-ene derivatives with an endo-oriented substituent at the 7-position [14-21]. Another method of synthesis of 2-oxaadamantane derivatives involves cyclization with participation of exocyclic bonds. Bicyclo[3.3.1]nonane-3,7-dione and 7-methylidenebicyclo[3.3.1]nonan-3-one are widely used as substrates in this reaction. Intermediately formed endofunctional bicyclo[3.3.1]nonane derivatives are capable of undergoing transannular cyclization through the second double bond. A number of 1-substituted and 1,3-disubstituted 2-oxaadamantanes were synthesized using this method [5, 8, 9, 12, 22-33].

The second strategy utilizes oxidative transformations of polycyclic cage structures and is based on cleavage of oxahomoadamantane derivatives obtained from 2-substituted adamantanes. The oxidation of 2-methyladamantan-2-ol and 2-phenyladamantan-2-ol with $\mathrm{Pb}(\mathrm{OAc})_{4} / \mathrm{I}_{2}$ gave oxahomoadamantane derivatives which were subjected to acid-catalyzed cleavage to produce 2-oxaadamantane structures [34-36]. Similar transformations can be conducted using adamantan2-one and adamantan-2-ol as initial compounds and $m$-CPBA as an oxidant [37-39]. In 1996, Krasutsky et al. [40] reported a new approach to the synthesis of 2-oxaadamantane via rearrangement of peroxy ester generated in situ from 2-methyladamantan-2-ol by the action of trifluoroperacetic acid according to the Criegee mechanism [41]. This approach was then extended to 2-methyladamantan-2-yl trifluoroacetate [42] and higher diamantoids [43].

Thus, the known methods for the synthesis of 2-oxaadamantane and its derivatives utilize mainly bicyclo[3.3.1]nonanes as initial compounds. These methods are sophisticated since the synthesis of initial 


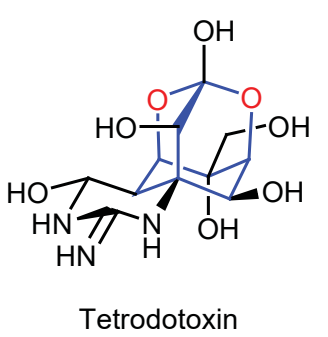

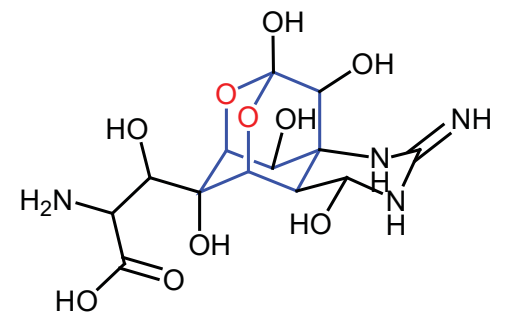

Chiriquitoxin

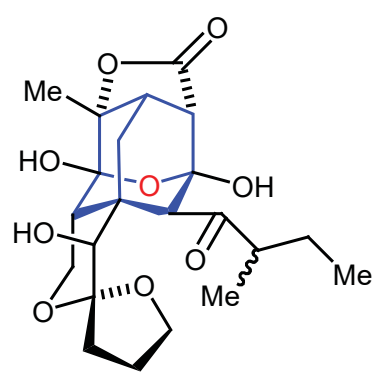

Fusidilactone C

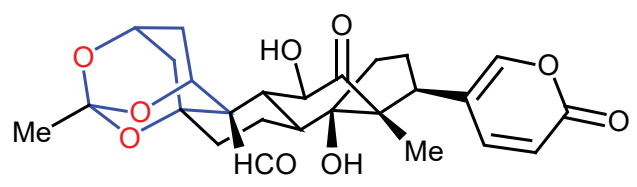

Daigremontianin<smiles>Cc1ncc(CO)c(C23OC4(O)CC(O)(CC(O)(C4)O2)O3)c1O</smiles>

Bananin

Fig. 1. Some natural compounds containing an oxaadamantane fragment.

bicyclic structures is often quite laborious. In some cases, a common drawback of both strategies is the use of expensive reagents and solvents. In this connection, there is a need to find readily available substrates and reagents that would allow target 2-oxaadamantanes to be synthesized in a single step. Such substrates may be 1,3-dihaloadamantanes as they are synthetically available compounds convenient for the preparation of various functional derivatives.

\section{RESULTS AND DISCUSSION}

We previously showed that the reaction of 1,3-dichloroadamantane with fuming nitric acid, including in the presence of acetic anhydride, involves nitrolysis with the formation of 3-chloroadamantan-1-yl nitrate and adamantane-1,3-diyl dinitrate [44, 45]. Change of the reaction conditions (no acetic anhydride, room temperature) led to the formation of a mixture of products having 2-oxaadamantane structure. The reaction of 1,3-dichloro-5,7-dimethyladamantane (1) with fuming nitric acid at room temperature gave a mixture of compounds $2-4$ at a ratio of 66.1:32.6:1.3 after $3 \mathrm{~h}$ (according to the GLC data; Scheme 1). We succeeded in isolating pure compounds $\mathbf{2}$ and $\mathbf{3}$ by flash chromatography.

The product structure was determined by NMR spectroscopy using ${ }^{1} \mathrm{H}-{ }^{13} \mathrm{C}$ HMBC and ${ }^{1} \mathrm{H}-{ }^{13} \mathrm{C}$ HSQC techniques. The ${ }^{1} \mathrm{H}$ NMR spectrum of 2 showed a singlet at $\delta 0.96 \mathrm{ppm}$ due to methyl protons. The singlet at $\delta 2.70 \mathrm{ppm}$ was assigned to the $\mathrm{OH}$ proton, and methylene protons of the chloromethyl group resonated as a singlet at $\delta 3.44 \mathrm{ppm}$. The quaternary carbon atom bearing $\mathrm{OH}$ group gave a signal at $\delta_{\mathrm{C}} 96.5 \mathrm{ppm}$ in the ${ }^{13} \mathrm{C}$ NMR spectrum. Protons of the chloromethyl group showed HMBC correlations with $\mathrm{C}^{4} / \mathrm{C}^{10}$ and $\mathrm{C}^{3}$ $\left(\delta_{\mathrm{C}} 42.8\right.$ and 76.4 ppm, respectively; Fig. 2 ). The structure of $\mathbf{2}$ was unambiguously proved by X-ray analysis of its single crystal which was grown from a solution in petroleum ether (Fig. 3). The mass spectrum of 2 showed the molecular ion peak $(\mathrm{m} / \mathrm{z} 230)$.

In the ${ }^{1} \mathrm{H}$ NMR spectrum of $\mathbf{3}$, protons of the methyl groups resonated as two singlets at $\delta 0.97$ and

\section{Scheme 1.}

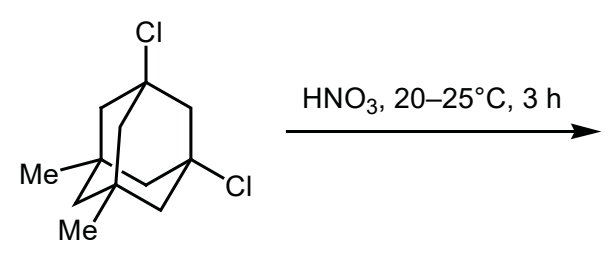

1

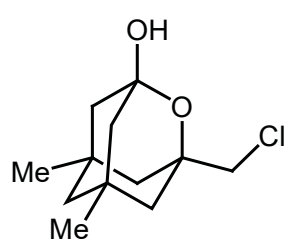

2

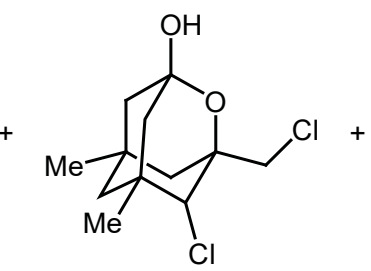

3

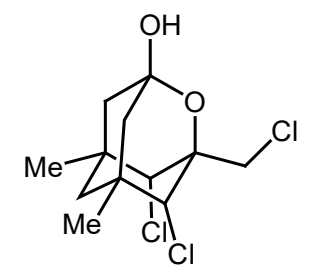

4 


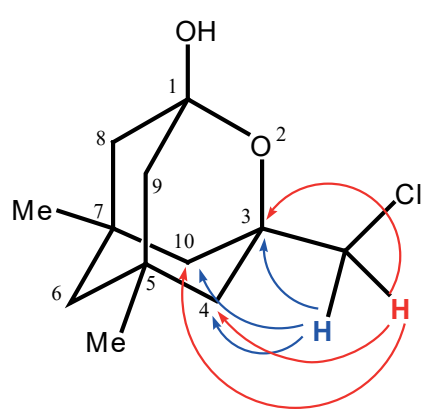

Fig. 2. Selected long-range couplings in the ${ }^{1} \mathrm{H}-{ }^{13} \mathrm{C}$ HMBC spectrum of compound 2 .

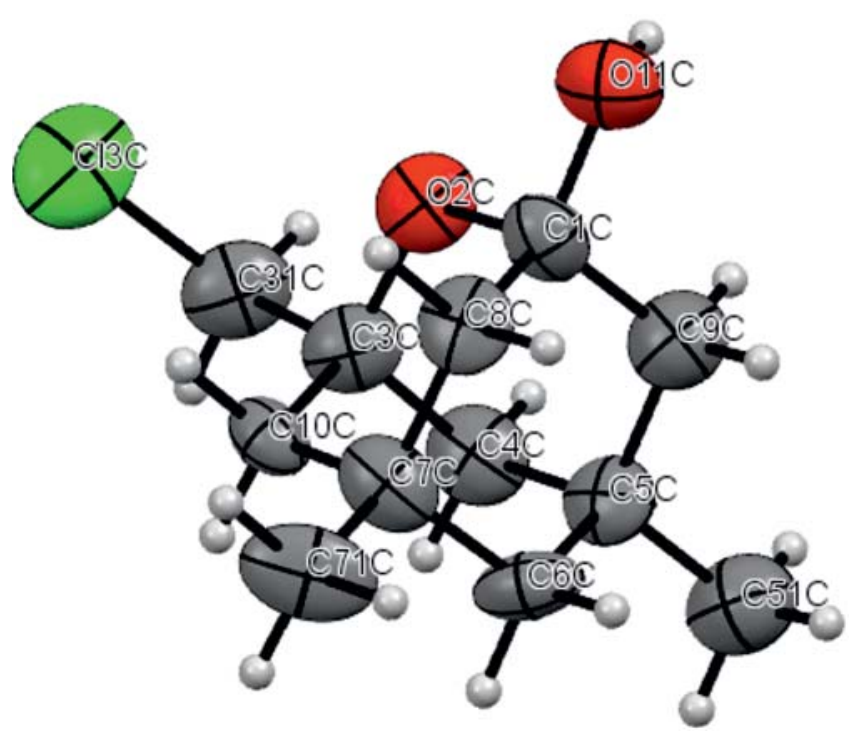

Fig. 3. Structure of the molecule of 2 according to the X-ray diffraction data. Non-hydrogen atoms are shown as thermal vibration ellipsoids with a probability of $30 \%$ [46].

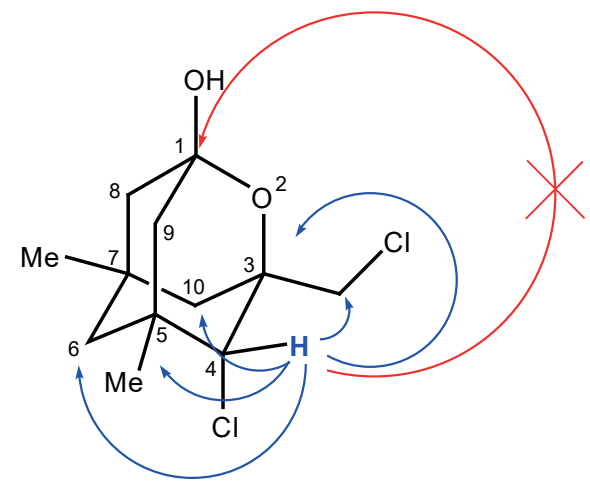

Fig. 4. Selected long-range couplings in the ${ }^{1} \mathrm{H}-{ }^{13} \mathrm{C}$ HMBC spectrum of compound $\mathbf{3}$.

$1.07 \mathrm{ppm}$, and the $\mathrm{OH}$ proton signal was a broadened singlet at $\delta 3.19 \mathrm{ppm}$. Protons of the chloromethyl group appeared as two doublets at $\delta 3.52$ and $3.73 \mathrm{ppm}$ with a coupling constant ${ }^{2} J$ of $11.7 \mathrm{~Hz}$, and the $\mathrm{CHCl}$ proton gave a singlet at $\delta 3.96 \mathrm{ppm}$. The ${ }^{13} \mathrm{C}$ NMR spectrum of 3 showed a signal at $\delta_{\mathrm{C}} 95.8 \mathrm{ppm}$ due to carbon atom linked to the hydroxy group, upfield signals at $\delta_{\mathrm{C}} 26.7$ and $28.8 \mathrm{ppm}$ due to methyl carbons, and a signal at $\delta_{\mathrm{C}} 66.0 \mathrm{ppm}$ from the $\mathrm{CHCl}$ carbon atom. The ${ }^{1} \mathrm{H}-{ }^{13} \mathrm{C}$ HMBC spectrum of 3 (Fig. 4) displayed correlations between the $\mathrm{CHCl}$ proton ( $\delta 3.96 \mathrm{ppm}$ ) and $\mathrm{C}^{3}, \mathrm{C}^{10}, \mathrm{C}^{5}, \mathrm{C}^{6}$, and $\mathrm{CH}_{2} \mathrm{Cl}$ carbons $\left(\delta_{\mathrm{C}} 78.4,37.2,37.4,42.0\right.$, and $49.8 \mathrm{ppm}$, respectively). The $\mathrm{ClCH}_{2}$ proton resonating at $\delta 3.52 \mathrm{ppm}$ was coupled with $\mathrm{C}^{3}$ and $\mathrm{C}^{4}\left(\delta_{\mathrm{C}} 78.4\right.$ and $66.0 \mathrm{ppm}$, respectively), whereas no correlation with $\mathrm{C}^{1}\left(\delta_{\mathrm{C}} 95.8 \mathrm{ppm}\right)$ was observed. The molecular ion peak $(\mathrm{m} / \mathrm{z} 264)$ in the mass spectrum of $\mathbf{3}$ had a low intensity.

The reaction proceeded through intermediate formation of 3-chloro-5,7-dimethyladamantan-1-yl nitrate (5) and 5,7-dimethyladamantane-1,3-diyl dinitrate (6) [44]. After $10 \mathrm{~min}$ from the reaction start, the fractions of 2-oxaadamantanes $\mathbf{2}, \mathbf{3}$, and $\mathbf{4}$ were $9.3,4.8$, and $0.6 \%$, respectively (GLC), and the fraction of nitroxy derivatives amounted to $85.3 \%$. By recrystallization of the obtained product mixture from methanol we isolated 5,7-dimethyladamantane-1,3-diyl dinitrate (6) whose structure was confirmed by ${ }^{1} \mathrm{H}$ and ${ }^{13} \mathrm{C}$ NMR spectra.

Presumably, protonation of $\mathbf{5}$ at the $\mathrm{ONO}_{2}$ group, followed by elimination of nitric acid molecule, gives carbocation A which undergoes Grob fragmentation [47], and a sequence of subsequent transformations leads to the formation of 7-methylidenebicyclo[3.3.1]nonan-3-one (B). The latter adds liberated chlorine at the exocyclic double bond, and further reaction with $\mathrm{HNO}_{3}$, transannular cyclization, and elimination of nitronium cation yield compound $\mathbf{2}$ (Scheme 2). Hemiacetal $\mathbf{2}$ is likely to exist in equilibrium with its open ketone structure $\mathbf{C}$. Its dehydration gives bicyclononene derivative $\mathbf{D}$ which undergoes electrophilic attack by chlorine generated via oxidation of chloride ion with fuming nitric acid. Cation $\mathbf{E}$ thus formed adds nitrate ion, and the subsequent cyclization furnishes dichloro derivative $\mathbf{3}$. Dichloride 3 can be converted to trichloride $\mathbf{4}$ according to a similar transformation sequence (Scheme 3).

The structure of hydroxy ketone $\mathbf{C}$ suggests an alternative mechanism of introduction of the second chlorine atom into molecule 2 through the enol form of C. However, the ${ }^{1} \mathrm{H}-{ }^{13} \mathrm{C}$ HMBC spectrum of $\mathbf{3}$ unambiguously indicated the position of the second chlorine atom: as noted above, no correlation between the 4-H proton and $\mathrm{C}^{1}$ was observed (Fig. 4).

The proposed mechanism of the transformation of dichloroadamantane 1 into 2-oxaadamantane deriva- 
Scheme 2.
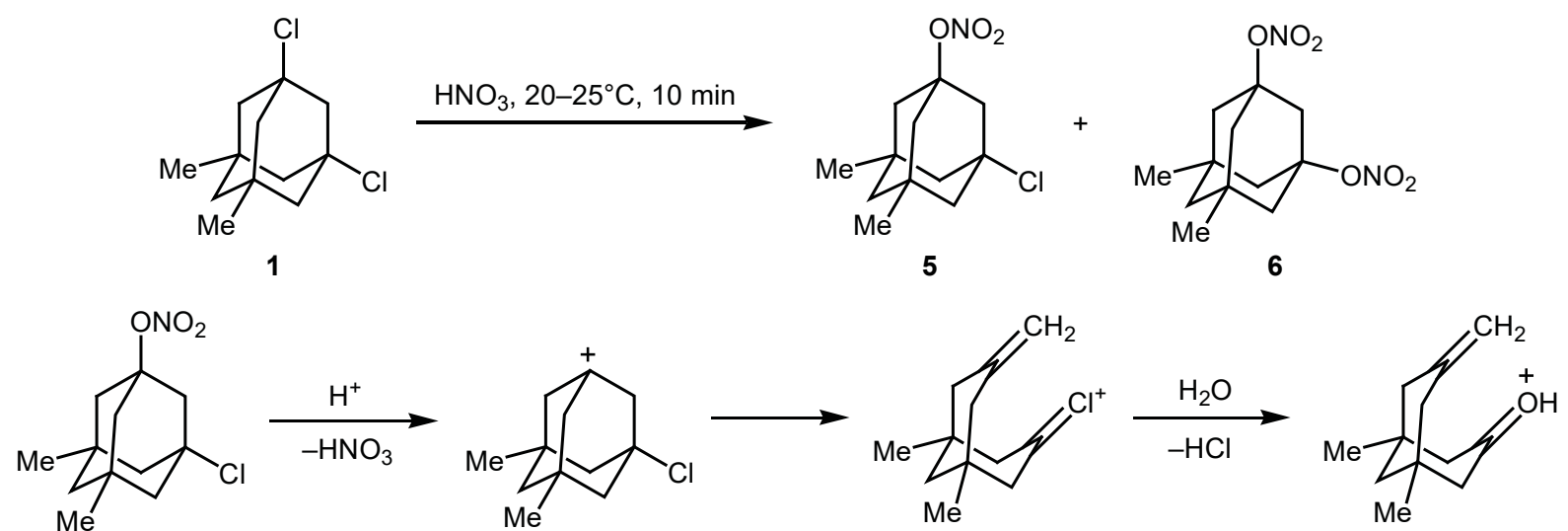

5

A

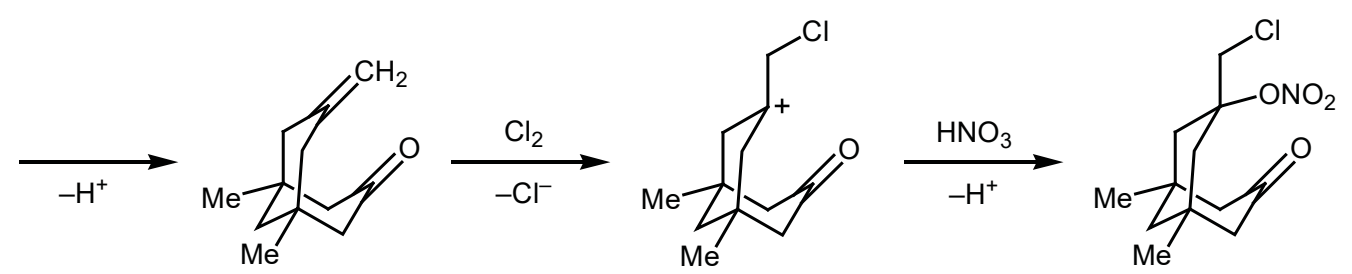

B

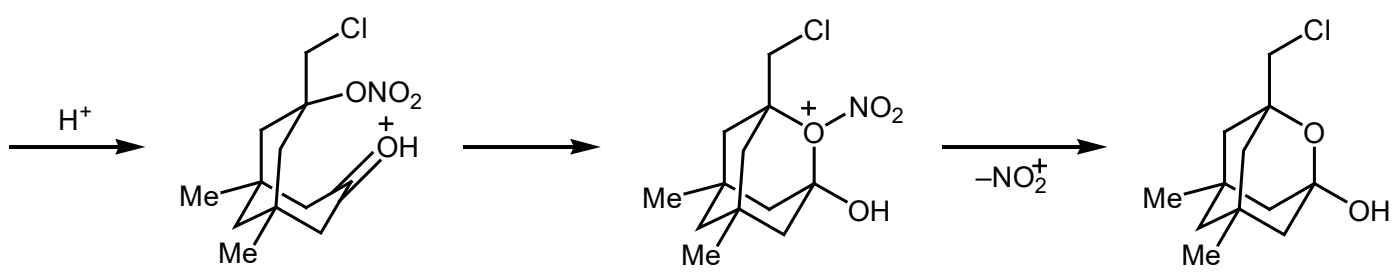

2

Scheme 3.<smiles>CC1(C)CC2(O)CC(C)(C)OC(CCl)(C1)C2</smiles>

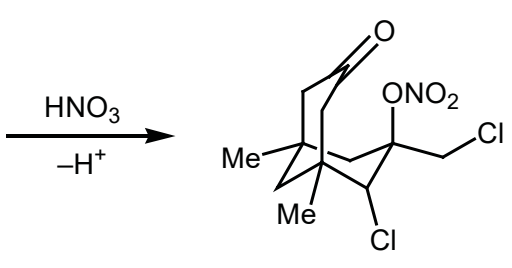<smiles></smiles><smiles>CC1(C)CC2(O)CC(C)(C)C(CCl)(O2)C1Cl</smiles>

3

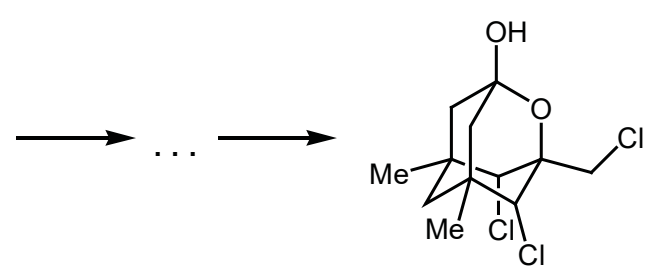

4 tives 2-4 explains why the selective synthesis of compound $\mathbf{2}$ is hardly probable. The reason is that the formation of $\mathbf{2}$ from intermediate nitroxy derivative $\mathbf{5}$ and its further conversion to dichloride $\mathbf{3}$ are concurrent processes. On the other hand, an increase of the reac- tion time, including at elevated temperature $\left(40^{\circ} \mathrm{C}\right)$, makes it possible to change the product ratio toward almost exclusive formation of dichloride $\mathbf{3}$ and trichloride 4. However, the yield simultaneously decreases due to increased contribution of deeper oxidative trans- 


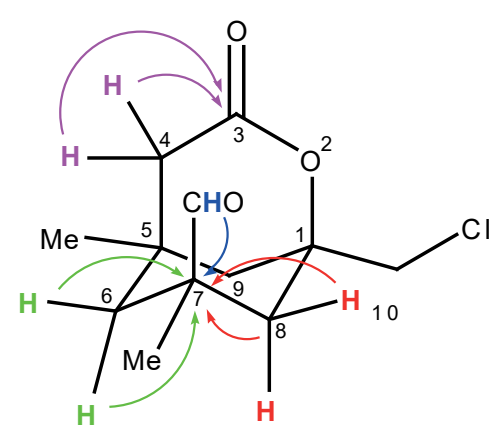

Fig. 5. Selected long-range couplings in the ${ }^{1} \mathrm{H}-{ }^{13} \mathrm{C}$ HMBC spectrum of compound 7 .

formations. For example, when the reaction mixture was heated under reflux for a short time, 1-chloromethyl-5,7-dimethyl-3-oxo-2-oxabicyclo[3.3.1]nonane-7-carbaldehyde (7) was formed in addition to compounds 3 and $\mathbf{4}$. The structure of 7 was confirmed by ${ }^{1} \mathrm{H}$ and ${ }^{13} \mathrm{C}$ NMR spectra, including 2D NMR experiments.

The ${ }^{13} \mathrm{C}$ NMR spectrum of 7 contained carbonyl carbon signals at $\delta_{\mathrm{C}} 169.4$ and $202.9 \mathrm{ppm}$. The ${ }^{1} \mathrm{H}-{ }^{13} \mathrm{C}$ HMBC spectrum clearly showed correlations between the $4-\mathrm{H}$ protons $\left(\delta 2.17,2.44 \mathrm{ppm} ; \delta_{\mathrm{C}^{4}} 42.5 \mathrm{ppm}\right)$ and $\mathrm{C}^{3}\left(\delta_{\mathrm{C}} 169.4 \mathrm{ppm}\right)$, as well as between the aldehyde proton $(\delta 9.36 \mathrm{ppm})$ and $\mathrm{C}^{7}\left(\delta_{\mathrm{C}} 45.4 \mathrm{ppm}\right)$. The latter in turn was coupled with protons of one methyl group resonating at $\delta 1.09 \mathrm{ppm}$ and protons on $\mathrm{C}^{6}$ and $\mathrm{C}^{8}$ (Fig. 5). The other correlations also confirmed the proposed structure.

Under similar conditions, from 1,3-dichloroadamantane (8) as substrate we obtained a mixture of 2-oxaadamantane derivatives 9-11 which we failed to separate by flash chromatography or recrystallization (Scheme 4). After keeping the reaction mixture for $24 \mathrm{~h}$, it contained $81 \%$ (GLC) of 4-chloro-3-chloromethyl-2-oxaadamantan-1-ol (10). Pure compound 10 was isolated from that mixture by recrystallization from carbon tetrachloride. In the ${ }^{1} \mathrm{H}$ NMR spectrum of 10, the 4-H proton resonated as a singlet at $\delta 4.33 \mathrm{ppm}$. Methylene protons of the chloromethyl group appeared as two doublets at $\delta 3.49$ and 3.64 ppm with a coupling constant of $11.6 \mathrm{~Hz}$. In the ${ }^{13} \mathrm{C}$ NMR spectrum of $\mathbf{1 0}$, the $\mathrm{C}^{4}$ signal was located at $\delta_{\mathrm{C}} 60.5 \mathrm{ppm}$, and the signal at $\delta_{\mathrm{C}} 94.8 \mathrm{ppm}$ was assigned to the quaternary carbon atom bearing the hydroxy group.

\section{EXPERIMENTAL}

The IR spectra were recorded on a Shimadzu IR Affinity-1 spectrometer (Japan). The ${ }^{1} \mathrm{H}$ and ${ }^{13} \mathrm{C}$ NMR spectra were recorded on a Jeol ECX-400 spectrometer (Japan) at 400 and $100 \mathrm{MHz}$, respectively, using tetramethylsilane as internal standard. The mass spectra (electron impact, $70 \mathrm{eV}$ ) were run on a Finnigan Trace DSQ instrument. The reaction mixtures were analyzed with a Thermo Scientific Focus gas chromatograph (USA) using a DB-5 capillary column, $30 \mathrm{~m} \times 0.32 \mathrm{~mm}$ (oven temperature programming from 80 to $340^{\circ} \mathrm{C}$ at a rate of $20 \mathrm{deg} / \mathrm{min}$; injector temperature $250^{\circ} \mathrm{C}$; carrier gas helium). Flash chromatography was performed using a Buchi Reveleris X2 system (Switzerland); sorbent silica gel $(25-40 \mu \mathrm{m}, 12 \mathrm{~g})$, flow rate $20 \mathrm{~mL} / \mathrm{min}$. The melting points were measured in capillaries on an MPM-H2 melting point apparatus (Germany) and are uncorrected. Elemental analyses were carried out with a Euro Vector 3000 EA analyzer (Italy) using L-cystine as standard. The purity of the isolated compounds was no less than $96.0 \%$.

1,3-Dichloro-5,7-dimethyladamantane (1) was synthesized according to the procedure described in [48].

Reaction of 1,3-dichloro-5,7-dimethyladamantane (1) with fuming nitric acid. Fuming nitric acid, $2.2 \mathrm{~mL}(0.054 \mathrm{~mol})$, was added with stirring at room temperature over a period of $5 \mathrm{~min}$ to a solution of $0.5 \mathrm{~g}(2.14 \mathrm{mmol})$ of 1,3-dichloro-5,7-dimethyladamantane (1) in $0.5 \mathrm{~mL}$ of methylene chloride. The mixture was stirred for $3 \mathrm{~h}$, poured onto crushed ice, and extracted with methylene chloride $(4 \times 10 \mathrm{~mL})$. The combined extracts were successively washed with a solution of sodium bisulfite $(2 \times 10 \mathrm{~mL}), 10 \%$ aqueous sodium hydroxide $(1 \times 10 \mathrm{~mL})$, and water, dried over anhydrous sodium sulfate, and evaporated under

\section{Scheme 4.}

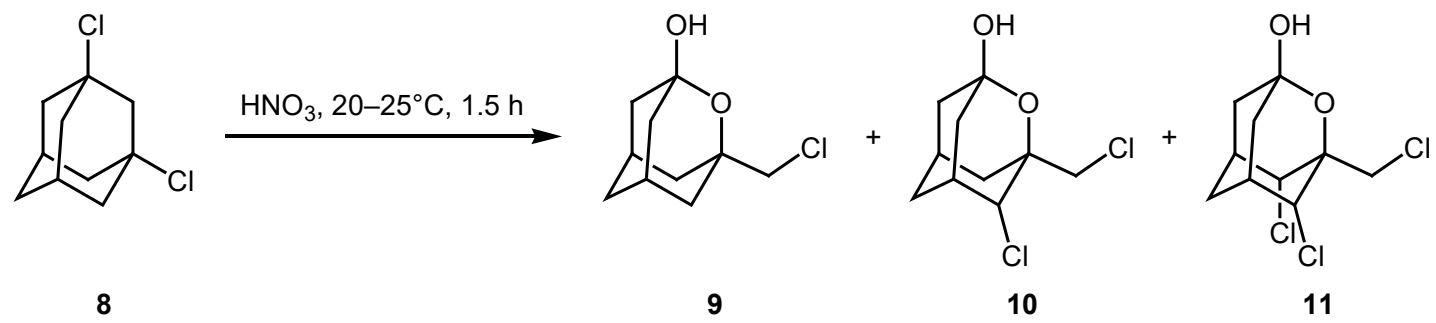

RUSSIAN JOURNAL OF ORGANIC CHEMISTRY Vol. 58 No. 12022 
reduced pressure. According to the GLC data, the residue contained $66.1 \%$ of $2,32.6 \%$ of 3 , and $1.3 \%$ of 4 . The product mixture was separated by flash chromatography; gradient elution with chloroform (6 min) and chloroform-ethanol (0 to 3\% EtOH, $3 \mathrm{~min}$; 3 to $12 \% \mathrm{EtOH}, 3 \mathrm{~min}$ ); flow rate $20 \mathrm{~mL} / \mathrm{min}$. We isolated pure compounds $\mathbf{2}$ and $\mathbf{3}$ and a 5.5:1 mixture of 3 and 4.

3-(Chloromethyl)-5,7-dimethyl-2-oxaadamantan-1-ol (2). Yield $0.17 \mathrm{~g}(35 \%)$, colorless crystals, $\mathrm{mp} 82.5-84^{\circ} \mathrm{C}$ (from hexane). IR spectrum, $\mathrm{v}, \mathrm{cm}^{-1}$ : $3425(\mathrm{OH}), 2945,2922,2864,2845(\mathrm{CH}) .{ }^{1} \mathrm{H}$ NMR spectrum $\left(\mathrm{CDCl}_{3}\right), \delta$, ppm: $0.96 \mathrm{~s}\left(6 \mathrm{H}, \mathrm{CH}_{3}\right), 1.20$ $1.21 \mathrm{~m}(2 \mathrm{H}, 6-\mathrm{H}), 1.25-1.40 \mathrm{~m}(6 \mathrm{H}, 4-\mathrm{H}, 8-\mathrm{H}, 10-\mathrm{H})$, $1.45-1.49 \mathrm{~m}(2 \mathrm{H}, 9-\mathrm{H}), 2.70 \mathrm{~s}(1 \mathrm{H}, \mathrm{OH}), 3.45 \mathrm{~s}(2 \mathrm{H}$, $\left.\mathrm{CH}_{2} \mathrm{Cl}\right) \cdot{ }^{13} \mathrm{C}$ NMR spectrum $\left(\mathrm{CDCl}_{3}\right), \delta_{\mathrm{C}}, \mathrm{ppm}: 29.2$ $\left(2 \mathrm{C}, \mathrm{CH}_{3}\right), 33.3\left(\mathrm{C}^{5}, \mathrm{C}^{7}\right), 42.8\left(\mathrm{C}^{4}, \mathrm{C}^{10}\right), 47.1\left(\mathrm{C}^{8}, \mathrm{C}^{9}\right)$, $48.3\left(\mathrm{C}^{6}\right), 51.8\left(\mathrm{CH}_{2} \mathrm{Cl}\right), 76.4\left(\mathrm{C}^{3}\right), 96.6\left(\mathrm{C}^{1}\right)$. Mass spectrum, $m / z\left(I_{\text {rel }}, \%\right): 230(20)[M]^{+}, 232(6)$ $[M+2]^{+}, 215$ (4), 195 (2), 194 (4), 181 (100), 138 (50). Found, \%: C 62.56; $\mathrm{H} 8.20 . \mathrm{C}_{12} \mathrm{H}_{19} \mathrm{ClO}_{2}$. Calculated, \%: C 62.47; H 8.30.

anti-4-Chloro-3-(chloromethyl)-5,7-dimethyl-2oxaadamantan-1-ol (3). Yield $0.1 \mathrm{~g}(18 \%)$, colorless crystals, mp $92-94^{\circ} \mathrm{C}$. IR spectrum, $v, \mathrm{~cm}^{-1}: 3412$ (OH), 2947, 2924, 2868, $2848(\mathrm{CH}) .{ }^{1} \mathrm{H}$ NMR spectrum $\left(\mathrm{CDCl}_{3}\right), \delta$, ppm: $0.97 \mathrm{~s}\left(3 \mathrm{H}, \mathrm{CH}_{3}\right), 1.04 \mathrm{~s}(3 \mathrm{H}$, $\left.\mathrm{CH}_{3}\right), 1.02-1.06 \mathrm{~m}(1 \mathrm{H}, 6-\mathrm{H}), 1.15 \mathrm{~d}\left(1 \mathrm{H}, 10-\mathrm{H},{ }^{2} J=\right.$ $13.1 \mathrm{~Hz}), 1.42-1.53 \mathrm{~m}(2 \mathrm{H}, 8-\mathrm{H}), 1.67-1.72 \mathrm{~m}(3 \mathrm{H}$, 6-H, 9-H), $1.76 \mathrm{~d}\left(1 \mathrm{H}, 10-\mathrm{H},{ }^{2} J=13.1 \mathrm{~Hz}\right), 3.19$ br.s $(1 \mathrm{H}, \mathrm{OH}), 3.52 \mathrm{~d}$ and $3.73 \mathrm{~d}\left(1 \mathrm{H}\right.$ each, $\mathrm{CH}_{2} \mathrm{Cl},{ }^{2} \mathrm{~J}=$ $11.7 \mathrm{~Hz}), 3.96 \mathrm{~s}(1 \mathrm{H}, 4-\mathrm{H}) .{ }^{13} \mathrm{C}$ NMR spectrum $\left(\mathrm{CDCl}_{3}\right), \delta_{\mathrm{C}}, \mathrm{ppm}: 26.7\left(\mathrm{CH}_{3}\right), 28.8\left(\mathrm{CH}_{3}\right), 32.7\left(\mathrm{C}^{7}\right)$, $37.2\left(\mathrm{C}^{10}\right), 37.4\left(\mathrm{C}^{5}\right), 42.0\left(\mathrm{C}^{6}\right), 46.8\left(\mathrm{C}^{8}\right), 48.6\left(\mathrm{C}^{9}\right)$, $49.8\left(\mathrm{CH}_{2} \mathrm{Cl}\right), 66.0\left(\mathrm{C}^{4}\right), 78.4\left(\mathrm{C}^{3}\right), 95.8\left(\mathrm{C}^{1}\right)$. Mass spectrum, $m / z\left(I_{\text {rel }}, \%\right): 268$ (1) $[M+4]^{+}, 266$ (3) $[M+2]^{+}, 264(6)[M]^{+}, 253$ (1), 251 (6), 249 (9), 206 (12), 204 (18) 159 (24), 137 (34), 105 (52), 93 (64), 91 (100), 77 (78). Found, \%: C 54.44; H 6.76. $\mathrm{C}_{12} \mathrm{H}_{18} \mathrm{Cl}_{2} \mathrm{O}_{2}$. Calculated, \%: C 54.35; H 6.84.

Mixture of 3 and anti,anti-4,10-dichloro-3(chloromethyl)-5,7-dimethyl-2-oxaadamantan-1-ol (4). Ratio 3/4 5.5:1 (GLC). Mass spectrum of 4, $\mathrm{m} / \mathrm{z}$ $\left(I_{\text {rel }}, \%\right): 302(2)[M+4]^{+}, 300(4)[M+2]^{+}, 298$ (7) $[M]^{+}, 265$ (8), 263 (8), 241 (60), 91 (100), 77 (84).

5,7-Dimethyladamantane-1,3-diyl dinitrate (6). Fuming nitric acid, $2.2 \mathrm{~mL}(0.054 \mathrm{~mol})$, was added with stirring at room temperature over a period of $5 \mathrm{~min}$ to a solution of $0.5 \mathrm{~g}(2.14 \mathrm{mmol})$ of 1,3 -di- chloro-5,7-dimethyladamantane (1) in $0.5 \mathrm{~mL}$ of methylene chloride. The mixture was stirred for $10 \mathrm{~min}$, poured onto crushed ice, and extracted with methylene chloride $(4 \times 10 \mathrm{~mL})$. The combined extracts were successively washed with a solution of sodium bisulfite $(2 \times 10 \mathrm{~mL}), 10 \%$ aqueous sodium hydroxide $(1 \times 10 \mathrm{~mL})$, and water, dried over anhydrous sodium sulfate, and evaporated under reduced pressure, and the residue was recrystallized from methanol. Yield $45 \%$, colorless crystals, $\mathrm{mp} 43-45^{\circ} \mathrm{C}$ [49].

1-Chloromethyl-5,7-dimethyl-3-oxo-2-oxabicyclo[3.3.1]nonan-7-carbaldehyde (7) was obtained when a mixture of $1.5 \mathrm{~g}(6 \mathrm{mmol})$ of dichloride 1 and $30 \mathrm{~mL}(0.72 \mathrm{~mol})$ of fuming nitric acid was kept for 4 days at room temperature, followed by heating under reflux for $20 \mathrm{~min}$. The product was isolated by flash chromatography using carbon tetrachloride- $t$-butyl methyl ether as eluent. Yield $0.2 \mathrm{~g}(12 \%)$, colorless crystals. ${ }^{1} \mathrm{H}$ NMR spectrum $\left(\mathrm{CDCl}_{3}\right), \delta$, ppm: $1.02 \mathrm{~s}$ $\left(3 \mathrm{H}, \mathrm{CH}_{3}\right), 1.09 \mathrm{~s}\left(3 \mathrm{H}, \mathrm{CH}_{3}\right), 1.12-1.18 \mathrm{~m}(1 \mathrm{H}, 9-\mathrm{H})$, 1.60-1.72 m (3H, 6-H, 8-H), 2.17 d.d $\left(1 \mathrm{H}, 4-\mathrm{H},{ }^{2} J=\right.$ $\left.19.0,{ }^{4} J=1.8 \mathrm{~Hz}\right), 2.35$ d.t $\left(1 \mathrm{H}, 9-\mathrm{H},{ }^{2} J=14.0,{ }^{4} J=\right.$ $2.0 \mathrm{~Hz}), 2.45$ d.t $\left(1 \mathrm{H}, 8-\mathrm{H},{ }^{2} J=14.6,{ }^{4} J=2.0 \mathrm{~Hz}\right)$, 2.53 d.d $\left(1 \mathrm{H}, 4-\mathrm{H},{ }^{2} J=19.0,{ }^{4} J=2.5 \mathrm{~Hz}\right), 3.58 \mathrm{q}(2 \mathrm{H}$, $\left.\mathrm{CH}_{2} \mathrm{Cl},{ }^{2} J=11.6 \mathrm{~Hz}\right), 9.36 \mathrm{~s}(1 \mathrm{H}, \mathrm{CHO}), 9.37 \mathrm{~s}(1 \mathrm{H}$, $\mathrm{CHO}) .{ }^{13} \mathrm{C}$ NMR spectrum $\left(\mathrm{CDCl}_{3}\right), \delta_{\mathrm{C}}, \mathrm{ppm}: 25.2$ $\left(\mathrm{CH}_{3}\right), 30.5\left(\mathrm{C}^{5}\right), 30.8\left(\mathrm{CH}_{3}\right), 39.7\left(\mathrm{C}^{6}\right), 41.6\left(\mathrm{C}^{8}\right), 42.0$ $\left(\mathrm{C}^{9}\right), 42.5\left(\mathrm{C}^{4}\right), 45.4\left(\mathrm{C}^{7}\right), 50.6\left(\mathrm{C}^{10}\right), 82.0\left(\mathrm{C}^{1}\right), 169.4$ $\left(\mathrm{C}^{3}\right), 202.9$ (CHO). Found, \%: C 58.97; H 6.92. $\mathrm{C}_{12} \mathrm{H}_{17} \mathrm{ClO}_{3}$. Calculated, \%: C 58.90; H 7.00.

Reaction of 1,3-dichloroadamantane (8) with fuming nitric acid. Fuming nitric acid, $2.5 \mathrm{~mL}$ (0.06 mol), was added with stirring at room temperature over a period of $5 \mathrm{~min}$ to a solution of $0.5 \mathrm{~g}(2.5 \mathrm{mmol})$ of 1,3-dichloroadamantane $(8)$ in $0.5 \mathrm{~mL}$ of methylene chloride. The mixture was stirred for $1.5 \mathrm{~h}$, poured onto crushed ice, and extracted with methylene chloride $(4 \times 10 \mathrm{~mL})$. The combined extracts were successively washed with a solution of sodium bisulfite $(2 \times 10 \mathrm{~mL})$, $10 \%$ aqueous sodium hydroxide $(1 \times 10 \mathrm{~mL})$, and water, dried over anhydrous sodium sulfate, and evaporated under reduced pressure. The residue was separated by flash chromatography; gradient elution with methylene chloride $(7 \mathrm{~min})$ and methylene chloride-ethanol (0 to $4 \% \mathrm{EtOH}, 4 \mathrm{~min}$; 4 to $10 \% \mathrm{EtOH}, 2 \mathrm{~min}$; 10 to $20 \%$ $\mathrm{EtOH}, 1.5 \mathrm{~min}$ ); flow rate $20 \mathrm{~mL} / \mathrm{min}$. We thus isolated a mixture of 3-(chloromethyl)-2-oxaadamantan-1-ol (9) and anti-4-chloro-3-(chloromethyl)-2-oxaadamantan-1-ol (10) at a ratio of 3:1 (GLC) and a mixture of 10 and anti,anti-4,10-dichloro-3-(chloromethyl)-2- 
oxaadamantan-1-ol (11) at a ratio of 1:2 Mass spectrum, $m / z\left(I_{\text {rel }}, \%\right): 9: 204(7)[M+2]^{+}, 202(30)[M]^{+}$, 167 (30), 166 (76), 124 (100), 107 (88); 10: 238 (8) $[M+2]^{+}, 236(20)[M]^{+}, 203(12), 201$ (58), 200 (38), $165(56) ; 11: 274(2)[M+4]^{+}, 272(<2)[M+2]^{+}, 270$ (4) $[M]^{+}, 239$ (4), 237 (20), 235 (28), 200 (6), 199 (20).

anti-4-Chloro-3-(chloromethyl)-2-oxaadamantan-1-ol (10). Fuming nitric acid, $5 \mathrm{~mL}(0.12 \mathrm{~mol})$, was added with stirring at room temperature over a period

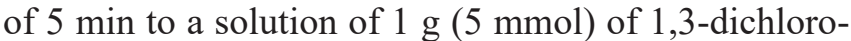
adamantane $(8)$ in $0.5 \mathrm{~mL}$ of methylene chloride. The mixture was stirred for $24 \mathrm{~h}$, poured onto crushed ice, and extracted with methylene chloride $(4 \times 10 \mathrm{~mL})$. The combined extracts were successively washed with a solution of sodium bisulfite $(2 \times 10 \mathrm{~mL}), 10 \%$ aqueous sodium hydroxide $(1 \times 10 \mathrm{~mL})$, and water, dried over anhydrous sodium sulfate, and evaporated under reduced pressure. The residue was recrystallized from carbon tetrachloride. Yield $0.46 \mathrm{~g}$ (40\%), colorless crystals, mp $121-123^{\circ} \mathrm{C} .{ }^{1} \mathrm{H}$ NMR spectrum $\left(\mathrm{CDCl}_{3}\right)$, $\delta$, ppm: $1.53 \mathrm{t}\left(2 \mathrm{H}, \mathrm{CH},{ }^{2} J=13.6 \mathrm{~Hz}\right), 1.74-1.87 \mathrm{~m}$ $(2 \mathrm{H}, \mathrm{CH}), 1.98 \mathrm{~s}(2 \mathrm{H}, \mathrm{CH}), 2.35-2.44 \mathrm{~m}(2 \mathrm{H}, \mathrm{CH})$, 2.99 br.s $(1 \mathrm{H}, \mathrm{OH}), 3.49 \mathrm{~d}$ and $3.64 \mathrm{~d}\left(1 \mathrm{H}\right.$ each, $\mathrm{CH}_{2} \mathrm{Cl}$, $\left.{ }^{2} J=11.6 \mathrm{~Hz}\right), 4.33 \mathrm{~s}(1 \mathrm{H}, \mathrm{CH}) .{ }^{13} \mathrm{C}$ NMR spectrum $\left(\mathrm{CDCl}_{3}\right), \delta_{\mathrm{C}}, \mathrm{ppm}: 28.0\left(\mathrm{CH}_{2}\right), 28.4(\mathrm{CH}), 30.9\left(\mathrm{CH}_{2}\right)$, $36.3(\mathrm{CH}), 40.9\left(\mathrm{CH}_{2}\right), 42.8\left(\mathrm{CH}_{2}\right), 49.8\left(\mathrm{CH}_{2}\right), 60.5$ $(\mathrm{CH}), 77.3$ ( $\left.\mathrm{C}_{\text {quat }}\right), 94.8$ ( $\left.\mathrm{C}_{\text {quat }}\right)$. Found, \%: C 50.74; $\mathrm{H}$ 5.88. $\mathrm{C}_{10} \mathrm{H}_{14} \mathrm{Cl}_{2} \mathrm{O}_{2}$. Calculated, \%: C 50.65; H 5.95.

$\mathrm{X}$-Ray analysis of compound 2. Single crystals of 2 suitable for X-ray analysis were obtained by slow evaporation of its solution in petroleum ether at room temperature. The X-ray diffraction data were collected using a Stoe StadiVari Pilatus-100K diffractometer ( $\mathrm{Cu} K_{\alpha}$ radiation). The structure was solved by the direct method and was refined by the full-matrix leastsquares method in anisotropic approximation for nonhydrogen atoms. All calculations were performed using SHELX [50], and the molecular structure was visualized by ORTEP [51]. The set of X-ray diffraction data for compound $\mathbf{2}$ was deposited to the Cambridge Crystallographic Data Centre (CCDC entry no. 1833287) [46].

\section{CONCLUSIONS}

A new method has been proposed for the synthesis of previously unknown 2-oxaadamantane derivatives by reaction of 1,3-dichloroadamantanes with fuming nitric acid. The reaction involves intermediate formation of the corresponding nitroxy derivatives which undergo skeletal transformations including Grob frag- mentation and transannular cyclizations. The synthesized 2-oxaadamantane derivatives can be used as starting materials for the preparation of biologically active compounds with a broad spectrum of action.

\section{AUTHOR INFORMATION}

E.A. Ivleva, ORCID: https://orcid.org/0000-0001-5778$860 \mathrm{X}$

V.B. Rybakov, ORCID: https://orcid.org/0000-00026720-0619

Yu.N. Klimochkin, ORCID: https://orcid.org/0000-00027335-4040

\section{ACKNOWLEDGMENTS}

This study was performed using the facilities of the "Investigation of Physicochemical Properties of Compounds and Materials" joint center at the Samara State Technical University and the Stoe StadiVari Pilatus 100K diffractometer purchased in the framework of a program for the development of the Moscow State University.

\section{FUNDING}

This study was performed under financial support by the Russian Science Foundation (project no. 20-73-00250). The spectral studies were financially supported by the Ministry of Science and Higher Education of the Russian Federation (project part of state assignment no. 0778-2020-0005).

\section{CONFLICT OF INTEREST}

The authors declare the absence of conflict of interest.

\section{REFERENCES}

1. Krohn, K., Biele, C., Drogies, K.H., Steingröver, K., Aust, H.J., Draeger, S., and Schulz, B., Eur. J. Org. Chem., 2002, vol. 2002, p. 2331.

https://doi.org/10.1002/1099-0690(200207)2002: 14<2331::AID-EJOC2331> 3.0.CO;2-P

2. Kesel, A.J., Bioorg. Med. Chem., 2003, vol. 11, p. 4599. https://doi.org/10.1016/S0968-0896(03)00500-5

3. Adedeji, A.O. and Sarafianos, S.G., Curr. Opin. Virol., 2014, vol. 8, p. 45.

https://doi.org/10.1016/j.coviro.2014.06.002

4. Kesel, A.J., Anti-Infect. Agents Med. Chem., 2006, vol. 5, p. 161.

5. Duque, M.D., Camps, P., Profire, L., Montaner, S., Vázquez, S., Sureda, F.X., Mallol, J., López-Querol, M., Naesens, L., De Clercq, E., Prathalingam, S.R., and Kelly, J.M., Bioorg. Med. Chem., 2009, vol. 17, p. 3198. https://doi.org/10.1016/j.bmc.2009.02.007 
6. Leiva, R., Gazzarrini, S., Esplugas, R., Moroni, A., Naesens, L., Sureda, F.X., and Vázquez, S., Tetrahedron Lett., 2015, vol. 56, p. 1272.

https://doi.org/10.1016/j.tetlet.2015.01.160

7. Codony, S., Pujol, E., Pizarro, J., Feixas, F., Valverde, E., Loza, M.I., Brea, J.M., Saez, E., Oyarzabal, J., PinedaLucena, A., Perez, B., Perez, C., RodríguezFranco, M.I., Leiva, R., Osuna, S., Morisseau, C., Hammock, B.D., Vazquez-Carrera, M., and Vazquez, S., J. Med. Chem., 2020, vol. 63, p. 9237. https://doi.org/10.1021/acs.jmedchem.0c00310

8. Ronco, C., Jean, L., and Renard, P.Y., Tetrahedron Lett., 2010, vol. 66, p. 7399.

https://doi.org/10.1016/j.tet.2010.07.021

9. Ronco, C., Foucault, R., Gillon, E., Bohn, P., Nachon, F., Jean, L., and Renard, P.Y., ChemMedChem, 2011, vol. 6, p. 876.

https://doi.org/10.1002/cmdc.201000523

10. Ho, T.C., Tius, M.A., Nikas, S.P., Tran, N.K., Tong, F., Zhou, H., Zvonok, N., and Makriyannis, A., Bioorg. Med. Chem., Lett., 2021, vol. 38, article ID 127882. https://doi.org/10.1016/j.bmcl.2021.127882

11. Mlinarić-Majerski, K. and Kragol, G., Tetrahedron, 2001, vol. 57, p. 449.

https://doi.org/10.1016/S0040-4020(00)01013-9

12. Marchand, A.P., Kumar, K.A., and McKim, A.S., Tetrahedron, 1997, vol. 53, p. 3467. https://doi.org/10.1016/S0040-4020(97)00075-6

13. Averina, N.V. and Zefirov, N.S., Russ. Chem. Rev., 1976, vol. 45 , p. 544. https://doi.org/10.1070/RC1976v045n06ABEH002680

14. Liu, J.H. and Kovacic, P., J. Org. Chem., 1973, vol. 38, p. 3462. https://doi.org/10.1021/jo00960a004

15. Subramaniam, R. and Fort, R.C., Jr., J. Org. Chem., 1984, vol. 49, p. 2891.

https://doi.org/10.1021/jo00190a010

16. Bubnov, Y.N., Grandberg, A.I., Grigorian, M.S., Kiselev, V.G., Struchkova, M.I., and Mikhailov, B.M., J. Organomet. Chem., 1985, vol. 292, p. 93. https://doi.org/10.1016/0022-328X(85)87325-3

17. Moon, S., Wright, D.G., and Schwartz, A.L., J. Org. Chem., 1976, vol. 41, p. 1899.

https://doi.org/10.1021/jo00873a003

18. Yokoshima, S., Ishikawa, M., Beniyama, Y., and Fukuyama, T., Chem. Pharm. Bull., 2016, vol. 64, p. 1528. https://doi.org/10.1248/cpb.c16-00507

19. Djaidi, D., Leung, I.S.H., Bishop, R., Craig, D.C., and Scudder, M.L., J. Chem. Soc., Perkin Trans. 1, 2000, p. 2037.

https://doi.org/10.1039/b002544p

20. Dixon, D.D., Sethumadhavan, D., Benneche, T., Banaag, A.R., Tius, M.A., Thakur, G.A., Bowman, A.,
Wood, J.T., and Makriyannis, A., J. Med. Chem., 2010, vol. 53, p. 5656.

https://doi.org/10.1021/jm100390h

21. Krishnamurthy, V.V. and Fort, R.C., Jr., J. Org. Chem., 1981, vol. 46, p. 1388. https://doi.org/10.1021/jo00320a033

22. Benneche, T. and Tius, M.A., Tetrahedron Lett., 2016, vol. 57, p. 3150 .

https://doi.org/10.1016/j.tetlet.2016.06.027

23. Stetter, H., Gärtner, J., and Tacke, P., Chem. Ber., 1966, vol. 99 , p. 1435.

https://doi.org/10.1002/cber.19660990502

24. Yeh, V.S.C., Kurukulasuriya, R., Madar, D., Patel, J.R., Fung, S., Monzon, K., Chiou, W., Wang, J., Jacobson, P., Sham, H.L., and Link, J.T., Bioorg. Med. Chem. Lett., 2006, vol. 16, p. 5408.

https://doi.org/10.1016/j.bmcl.2006.07.062

25. Camps, P., Gomez, E., Munoz-Torrero, D., FontBardia, M., and Solans, X., Tetrahedron, 2003, vol. 59, p. 4143. https://doi.org/10.1016/S0040-4020(03)00577-5

26. Meyer, W.P. and Martin, J.C., J. Am. Chem. Soc., 1976. vol. 98, p. 1231.

https://doi.org/10.1021/ja00421a030

27. Quast, H., Witzel, M., Peters, E.M., Peters, K., and von Schnering, H.G., Justus Liebigs Ann. Chem., 1995. vol. 1995 , p. 725.

https://doi.org/10.1002/jlac.1995199505108

28. Camps, P., El Achab, R., Görbig, D.M., Morral, J., Muñoz-Torrero, D., Badia, A., Baños, J.E., Vivas, N.M., Barril, X., Orozco, M., and Luque, F.J., J. Med. Chem., 1999. vol. 42, p. 3227.

https://doi.org/10.1021/jm980620z

29. Kubilius, R., Bagdžiūnas, G., and Butkus, E., Tetrahedron Lett., 2011, vol. 52, p. 346.

https://doi.org/10.1016/j.tetlet.2010.11.067

30. Mlinarić-Majerski, K., Kragol, G., and Ramljak, T.Š., Synlett, 2008, vol. 2008, p. 405.

https://doi.org/10.1055/s-2008-1032054

31. Camps, P., El Achab, R., Font-Bardia, M., Gorbig, D., Morral, J., Mufioz-Torrero, D., Solans, X., and Simon, M., Tetrahedron, 1996, vol. 52, p. 5867. https://doi.org/10.1016/0040-4020(96)00217-7

32. Stepanov, F.N., Utochka, T.N., and Yurchenko, A.G., Zh. Org. Khim., 1972, vol. 8, p. 1183.

33. Stepanov, F.N., Utochka, T.N., Yurchenko, A.G., and Isaev, S.D., Zh. Org. Khim., 1974, vol. 10, p. 59.

34. Black, R.M. and Gill, G.B., J. Chem. Soc. D, 1971, no. 3, p. 172. https://doi.org/10.1039/C29710000172

35. Black, R.M. and Gill, G.B., J. Chem. Soc., Perkin Trans. 1, 1980, p. 410. https://doi.org/10.1039/P19800000410

36. Marchand, A.P., Kumar, V.S., and Hariprakasha, H.K., J. Org. Chem., 2001, vol. 66, p. 2072. https://doi.org/10.1021/jo001611c 
37. Black, R.M., Gill, G.B., and Hands, D., J. Chem. Soc., Chem. Commun., 1972, no. 6, p. 311. https://doi.org/10.1039/C39720000311

38. Suginome, H. and Yamada, S., Tetrahedron Lett., 1984, vol. 25 , p. 3995 . https://doi.org/10.1016/0040-4039(84)80049-0

39. Suginome, H. and Yamada, S., Synthesis, 1986, vol. 1986, p. 741. https://doi.org/10.1055/s-1986-31761

40. Krasutsky, P.A., Kolomitsin, I.V., Carlson, R.M., and Jones, M., Jr., Tetrahedron Lett., 1996, vol. 37, p. 5673. https://doi.org/10.1016/0040-4039(96)01202-6

41. Criegee, R., Chem. Ber., 1945, vol. 77, p. 722. https://doi.org/10.1002/cber.19450770912

42. Krasutsky, P.A., Kolomitsyn, I.V., Kiprof, P., Carlson, R.M., and Fokin, A.A., J. Org. Chem., 2000, vol. 65 , p. 3926 . https://doi.org/10.1021/jo991745u

43. Fokin, A.A., Zhuk, T.S., Pashenko, A.E., Dral, P.O., Gunchenko, P.A., Dahl, J.E.P., Carlson, R.M.K., Koso, T.V., Serafin, M., and Schreiner, P.R., Org. Lett., 2009, vol. 11, p. 3068. https://doi.org/10.1021/o1901089h

44. Klimochkin, Yu.N., Ivleva, E.A., and Moiseev, I.K., Russ. J. Org. Chem., 2020, vol. 56, p. 1532. https://doi.org/10.1134/S1070428020090055
45. Klimochkin, Yu.N., Ivleva, E.A., and Skomorokhov, M.Yu., Russ. J. Org. Chem., 2020, vol. 56, p. 1525. https://doi.org/10.1134/S1070428020090043

46. Rybakov, V.B., Klepikov, V.V., Ivleva, E.A., and Klimochkin, Y.N., CCDC 1833287: Experimental Crystal Structure Determination, 2018. https://doi.org/10.5517/ccdc.csd.cc1zjp9h

47. Grob, C.A. and Baumann, W., Helv. Chim. Acta, 1955, vol. 38 , p. 594. https://doi.org/10.1002/hlca.19550380306

48. Lerman, B.M., Aref'eva, Z.Ya., Kuzyev, A.R., and Tolstikov, G.A., Bull. Acad. Sci. USSR, Div. Chem. Sci., 1971, vol. 20, p. 820.

https://doi.org/10.1007/BF00853945

49. Moiseev, I.K., Bagrii, E.I., Klimochkin, Yu.N., Dolgopolova, T.N., Trakhtenberg, P.L., and Zemtsova, M.N., Bull. Acad. Sci. USSR, Div. Chem. Sci., 1985, vol. 34, no. 9, p. 1980. https://doi.org/10.1007/BF00953950

50. Sheldrick, G.M., Acta Crystallogr., Sect. C, 2015, vol. 71, p. 3. https://doi.org/10.1107/S2053229614024218

51. Farrugia, L.J., J. Appl. Crystallogr., 2012, vol. 45, p. 849. https://doi.org/10.1107/S0021889812029111 